\title{
Free and esterified fatty acid and cholesterol synthesis in adult males and its effect on the doubly-labelled water method
}

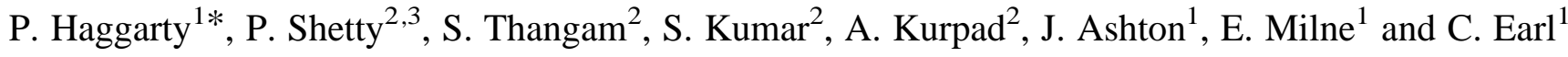 \\ ${ }^{1}$ Rowett Research Institute, Greenburn Road, Bucksburn, Aberdeen AB21 9SB, UK \\ ${ }^{2}$ Nutrition Research Centre, St John's Medical College, Bangalore, India \\ ${ }^{3}$ London School of Hygiene and Tropical Medicine, 2 Taviton Street, London WC1H OBT, UK
}

(Received 13 October 1998 - Revised 7 July 1999 - Accepted 17 August 1999)

\begin{abstract}
The purpose of the present study was to estimate whole-body fatty acid and cholesterol synthesis in weight-stable adults and to determine the likely effect on the doubly-labelled water (DLW) method for measuring energy expenditure. Synthesis was measured by ${ }^{2} \mathrm{H}$ incorporation over $14 \mathrm{~d}$ in six adult males in approximate energy balance following noradrenaline infusion to maximize mobilization of free fatty acid from adipose tissue. The inter-individual variation in synthesis rates was large and in one subject the proportion of free fatty acid synthesized was ten times that of the mean of the rest of the group; the fasting concentration of esterified fatty acid in this subject was five times that of the rest of the group indicating likely violation of the assumptions underlying the calculation of whole-body synthesis. After $14 \mathrm{~d}$ of labelling in the other five subjects, 0.9 (SEM 0.3 ) $\%$ of the circulating free fatty acid, 9.3 (SEM 3.0 ) $\%$ of the esterified fatty acid, 14.6 (SEM 2.4) \% of the free cholesterol and 28.3 (SEM 3.7) \% of esterified cholesterol had been synthesized de novo. A high rate of synthesis correlated with a low pre-dose ${ }^{2} \mathrm{H}$ abundance both within and between lipid classes suggesting that natural ${ }^{2} \mathrm{H}$ abundance variations in some lipid classes may be used to determine their metabolic origin. Whole-body synthetic rates were $8 \mathrm{~g} / \mathrm{d}$ for fatty acid and $0 \cdot 3-0.5 \mathrm{~g} / \mathrm{d}$ for cholesterol. These values correspond to very small errors on DLW-derived estimates of $\mathrm{CO}_{2}$ production; -2.5 litres/d for fatty acid and $-0 \cdot 1$ to $-0 \cdot 2$ litres/d for cholesterol. These results, obtained in subjects typically consuming a diet with a lower fat and cholesterol content that the typical Western diet, suggest that the DLW method is unlikely to be affected by fatty acid and cholesterol synthesis in subjects in energy balance consuming a typical Western diet.
\end{abstract}

Deuterium: Doubly-labelled water: Energy expenditure: Lipid synthesis

A basic assumption of the doubly-labelled water (DLW) method of measuring energy expenditure is that the $\mathrm{H}$ of body water only leaves the body water pool in the form of water (Lifson \& McLintock, 1966). If deuterium $\left({ }^{2} \mathrm{H}\right)$ was sequestered into products other than water during the course of a DLW study, this would result in an overestimate of water turnover and an underestimate of $\mathrm{CO}_{2}$ production (Haggarty, 1990) and it is ${ }^{2} \mathrm{H}$ incorporation into body fat in particular which has the greatest potential to affect the accuracy of the DLW method (Haggarty, 1990). We have previously shown, by direct measurement of ${ }^{2} \mathrm{H}$ incorporation into body fat, that the process of sequestration can result in an error on the DLW method of $-8 \%$ in rapidly growing pigs. This is a significant effect and, if repeated in human subjects, would represent a potentially serious error in the determination of energy requirements and even in relative measurements when comparing DLW-derived estimates of energy expenditure between groups with different intrinsic rates of fat synthesis. Simple estimates of fat deposition cannot be used to estimate sequestration since ${ }^{2} \mathrm{H}$ incorporation into fat can occur during the normal process of fat turnover; indeed fat synthesis has been detected in adult weight-stable human subjects from the long-term turnover of ${ }^{3} \mathrm{H}_{2} \mathrm{O}$ (Snyder et al. 1968) and the incorporation of ${ }^{2} \mathrm{H}$ into circulating fatty acid (Jones et al. 1988, 1994; Leitch \& Jones, 1991, 1993). However, the latter tracer studies have only been carried out over relatively short periods in relation to the likely rates of turnover of fat and cholesterol (Rittenberg \& Schoenheimer, 1937; Goodman et al. 1973). Fatty acid and cholesterol synthesis has been measured in adults over $15 \mathrm{~h}$ (Hellerstein et al. 1991), $24 \mathrm{~h}$ (Jones et al. 1994) and $48 \mathrm{~h}$ (Jones et al. 1988; Leitch \& Jones, 1991, 1993) and

\footnotetext{
Abbreviation: DLW, doubly-labelled water.

* Corresponding author: Dr Paul Haggarty, present address Nutrition and Early Development Laboratory, Department of Obstetrics and Gynaecology, University of Aberdeen, Aberdeen Maternity Hospital, Foresterhill, Aberdeen AB9 2ZD, UK, fax +44 (0)1224 684880, email p.haggarty@abdn.ac.uk
} 
cholesterol synthesis has been measured in infants over $60 \mathrm{~h}$ (Wong et al. 1993). However, interpretation of these rates of synthesis in relation to the DLW method is further complicated by the facts that these studies were not designed primarily to determine whole-body fatty acid synthesis and that different lipid classes in the circulation may represent distinct metabolic compartments. Pooling of these before analysis makes interpretation of the results more difficult. For example, Leitch \& Jones $(1991,1993)$ measured ${ }^{2} \mathrm{H}$ incorporation into triacylglycerol containing glycerol which may have also been enriched in ${ }^{2} \mathrm{H}$, Jones et al. (1994) measured ${ }^{2} \mathrm{H}$ incorporation into pooled samples of free and esterified cholesterol, whilst Jones et al. (1988) measured ${ }^{2} \mathrm{H}$ incorporation into free cholesterol only. The interpretation of some of these studies is further complicated by the fact that the plasma also contained dietary lipid as samples were taken in the fed state (see e.g. Hellerstein et al. 1991).

The aim of the study reported here was to measure de novo lipogenesis and cholesterol synthesis in both free and esterified fatty acid and cholesterol over the typical duration of a DLW study (2 weeks) and to determine the likely effects of sequestration on the performance of the DLW method in adult human subjects. In an attempt to obtain a fatty acid sample as representative as possible of the body stores, subjects underwent a noradrenaline infusion after overnight fast to maximize mobilization from body stores before sampling.

\section{Materials and methods}

\section{Subjects}

This study was approved by the Human Investigation Committee of St John's Medical College, Bangalore, India. All subjects gave informed consent to take part in the study. Six well-nourished Indian males (age 29 (SD 4) years; weight 63.73 (SD 9.97) kg; height 1.67 (SD 0.03) m; Table 1) took part in this study designed to quantify the likely effect of ${ }^{2} \mathrm{H}$ sequestration into body fat. Subjects consumed their normal diet during the labelling period and were in approximate energy balance, as assessed by body weight, throughout the experiment. All the subjects studied carried out non-manual work and had no known history of abnormal lipid metabolism (e.g. hyperlipidaemia) before recruitment. The diet of Indian males from urban areas $(30 \%$ energy as fat, cholesterol intake of $200 \mathrm{mg} / \mathrm{d}$; Begom \& Singh, 1995, 1997) is similar to the typical Western diet. Early morning blood samples $(200 \mathrm{ml})$ were taken after an overnight fast on days 0 and 14 . Before sampling on both days, subjects underwent a $30 \mathrm{~min}$ infusion of noradrenaline $(0 \cdot 15 \mu \mathrm{g} / \mathrm{kg}$ fat-free mass per min), designed to maximize fatty acid mobilization from body fat stores. Immediately after sampling on day 0 , subjects were given sufficient ${ }^{2} \mathrm{H}_{2} \mathrm{O}$ to raise the body water enrichment by approximately $500 \mathrm{ppm}$. The body water ${ }^{2} \mathrm{H}$ enrichment was maintained at $500 \mathrm{ppm}$ excess for $14 \mathrm{~d}$ by daily oral dosing each morning with ${ }^{2} \mathrm{H}_{2} \mathrm{O}$; the exact amount for each subject was calculated on the basis of water intake estimated previously from records kept by the subjects of water intake from liquids and food. Early morning urine samples were taken each day before ${ }^{2} \mathrm{H}_{2} \mathrm{O}$ dosing for the estimation of the average body water ${ }^{2} \mathrm{H}$ enrichment throughout the labelling period. The daily samples from each subject were then pooled and measured to determine the average ${ }^{2} \mathrm{H}$ abundance during the $14 \mathrm{~d}$ labelling period. The average ${ }^{2} \mathrm{H}$ enrichment in the plasma lipid fractions on day 14 relative to the average body water enrichment was used to calculate the proportion of circulating lipid which had been synthesized de novo during the labelling period.

\section{Analytical}

Lipid was extracted from the plasma by the method of Bligh \& Dyer (1959) after acidification to $\mathrm{pH} 3 \cdot 0-3 \cdot 5$ with $2 \mathrm{M}-\mathrm{HCl}$. The extracted lipid was then separated into lipid classes using $5 \mathrm{~g}$ amino-propyl normal phase bonded columns (Milipore UK Ltd, Watford, Herts, UK) as described by Kaluzny et al. (1985). The purity of the isolated lipid classes was checked by TLC on $200 \times 200 \mathrm{~mm}$ Al TLC plates coated with a $0.2 \mathrm{~mm}$ layer of silica-gel G60 (BDH-Merck Ltd, Poole, Dorset, UK). The mono-, di- and triacylglycerols were combined with the cholesterol ester fractions and saponified to give free fatty acids and cholesterol. Thus, the esterified fatty acid represents the fatty acid which was esterified to cholesterol or glycerol. The phospholipid fraction containing fatty acid was analysed separately. By mistake, the phospholipid was not hydrolysed to yield the free acid before combustion and therefore represents the only fraction which was not combusted as pure fatty acid or cholesterol.

Each lipid sample $(10 \mathrm{mg})$ in hexane was pipetted into a $200 \mathrm{~mm}$ length of pyrex tubing (o.d. $9 \mathrm{~mm}$, i.d. $6 \mathrm{~mm}$ ) sealed at one end and heated in a furnace at $530^{\circ}$ for $4 \mathrm{~h}$ in the presence of $800 \mathrm{mg}$ of $\mathrm{CuO}$ and a piece of $\mathrm{Ag}$ foil.

Table 1. Characteristics of subjects taking part in the present study

\begin{tabular}{|c|c|c|c|c|c|c|c|}
\hline \multirow[b]{2}{*}{ Subject } & \multirow{2}{*}{$\begin{array}{c}\text { Age } \\
\text { (years) }\end{array}$} & \multirow{2}{*}{$\begin{array}{l}\text { Height } \\
(\mathrm{m})\end{array}$} & \multirow{2}{*}{$\begin{array}{l}\text { Weight } \\
(\mathrm{kg})\end{array}$} & \multirow{2}{*}{$\begin{array}{c}\mathrm{BMl} \\
\left(\mathrm{kg} / \mathrm{m}^{2}\right)\end{array}$} & \multicolumn{2}{|c|}{ Fat mass } & \multirow{2}{*}{$\begin{array}{c}\text { Fat-free } \\
\text { mass }^{*} \\
(\mathrm{~kg})\end{array}$} \\
\hline & & & & & $(\%)$ & $(\mathrm{kg})$ & \\
\hline A & 34 & 1.69 & $72 \cdot 0$ & $25 \cdot 4$ & 29.5 & $21 \cdot 2$ & 50.8 \\
\hline B & 30 & 1.69 & 61.7 & 21.7 & 18.6 & 11.5 & 50.2 \\
\hline C & 23 & 1.71 & 64.9 & $22 \cdot 2$ & 13.1 & 8.5 & 56.4 \\
\hline D & 27 & 1.63 & 48.0 & $18 \cdot 1$ & 8.7 & $4 \cdot 2$ & 43.8 \\
\hline E & 28 & 1.67 & $76 \cdot 3$ & $27 \cdot 3$ & 21.5 & $16 \cdot 4$ & 59.9 \\
\hline $\mathrm{F}$ & 33 & 1.64 & 59.5 & $22 \cdot 1$ & $10 \cdot 8$ & $6 \cdot 4$ & 53.1 \\
\hline Mean & 29 & 1.67 & 63.7 & $22 \cdot 8$ & $17 \cdot 0$ & 11.4 & $52 \cdot 4$ \\
\hline SD & 4 & 0.03 & $10 \cdot 0$ & $3 \cdot 2$ & 7.8 & 6.4 & 5.5 \\
\hline
\end{tabular}

* Fat-free mass $=0.732 \times$ body water; body water $={ }^{2} \mathrm{H}_{2} \mathrm{O}$ space $/ 1.04$. 
After cooling, the bomb was carefully placed, with the narrow sealed end downwards, in a $30 \mathrm{ml}$ Yellow Cap (Young Scientific Glassware, London, UK) bottle. This was then evacuated, sealed, the bomb broken and the $\mathrm{Cu}$ released from the bomb by gently shaking the bottle. The water was then transferred under vacuum to a second bottle containing $500 \mathrm{mg} \mathrm{Zn} \mathrm{shot.} \mathrm{After} \mathrm{completion} \mathrm{of} \mathrm{the} \mathrm{transfer} \mathrm{and}$ re-evacuation, the bottle containing the frozen water and $\mathrm{Zn}$ was sealed and placed on a heating block at $475^{\circ}$ for $1 \mathrm{~h}$ to reduce the water to $\mathrm{H}_{2}$ gas. The deuterium enrichment of the $\mathrm{H}_{2}$ gas was determined by isotope-ratio mass spectroscopy on a SIRA 10 (VG, Middlewich, Ches., UK) mass spectrometer. Two internal standards of known ${ }^{2} \mathrm{H}$ abundance (palmitic acid; ${ }^{2} \mathrm{H}$ abundance $115 \mathrm{ppm}$ and $147 \mathrm{ppm}$ ) and one international standard, also of known ${ }^{2} \mathrm{H}$ abundance (PEF; International Atomic Energy Agency, Vienna, Austria) were included in each batch of twenty analyses (eleven biological samples, six laboratory reference palmitic acid samples and three International Atomic Energy Agency reference material samples) for the calculation of absolute ${ }^{2} \mathrm{H}$ abundance in the biological samples and to monitor for any isotope fractionation during combustion, water transfer and reduction. The average standard deviation on repeat measurements of biological samples was $1 \cdot 1 \mathrm{ppm}$. There was no difference in the precision of measurement between natural abundance and ${ }^{2} \mathrm{H}$-enriched lipid samples.

\section{Calculations}

The $\mathrm{H}$ of body water is in equilibrium with the $\mathrm{H}$ of NADPH and therefore incorporated into fatty acid and cholesterol during reductive biosynthesis (see e.g. Jungas, 1968; Dietschy \& Spady, 1984). When the body water $H$ is isotopically labelled, the incorporation of isotope may be used to calculate the proportion of fatty acid and cholesterol synthesized if the stoichiometry of $\mathrm{H}$ incorporation is known and the isotopic concentration of $\mathrm{H}$ in the precursor body water and lipid end product can be measured (Jungas, 1968; Deitschy \& Spady, 1984). Jungas (1968) estimated that ' $53 \%$ of the hydrogens of newly synthesised fatty acid would be derived from water as assayed with deuterium', therefore the fatty acid stoichiometry used here was 0.53 ; for cholesterol the value was 0.48 (Jones et al. 1993):

$$
\begin{aligned}
& \text { proportion of fatty acid synthesized de novo } \\
& =\frac{\text { fatty acid }{ }^{2} \mathrm{H} \text { concentration }(\mathrm{ppm} \text { excess })}{\text { water }{ }^{2} \mathrm{H} \text { concentration }(\mathrm{ppm} \text { excess }) \times 0.53}, \\
& \text { proportion of cholesterol synthesized de novo } \\
& =\frac{\text { cholesterol }{ }^{2} \mathrm{H} \text { concentration }(\mathrm{ppm} \text { excess })}{\text { water }{ }^{2} \mathrm{H} \text { concentration }(\mathrm{ppm} \text { excess }) \times 0.48} .
\end{aligned}
$$

\section{Statistics}

Means are presented in the text and figures together with the standard error of the mean (SEM); for purely descriptive data the standard deviation (SD) is given. The significance of differences between the means was calculated by twotailed $t$ test (Minitab Inc., Philadelphia, PA, USA). The fitting of equations to data was carried out using a graphic package; Origin (Microcal Software, Inc., Northampton, MA, USA).

\section{Results}

The body composition of the subjects was estimated from the increase in body water ${ }^{2} \mathrm{H}$ abundance after the initial dose of ${ }^{2} \mathrm{H}_{2} \mathrm{O}$. The proportion of body fat of this group ranged from 9 to $29 \%$ (Table 1 ). The average ${ }^{2} \mathrm{H}$ enrichment in the body water over the $14 \mathrm{~d}$ experimental period was 536 (SEM 33) ppm excess. The average value $4 \mathrm{~h}$ after the first dose was administered (i.e. after equilibration) was 535 (SEM 14) ppm excess. Thus, the plateau enrichment appeared to have been well maintained throughout the $14 \mathrm{~d}$ experimental period in this group by the daily ${ }^{2} \mathrm{H}_{2} \mathrm{O}$ dosing. The pre-dose ${ }^{2} \mathrm{H}$ abundances in the body water and each of the lipid fractions are presented in Table 2 . The ${ }^{2} \mathrm{H}$ abun-

\begin{tabular}{|c|c|c|c|c|c|c|c|c|c|c|c|c|}
\hline \multirow[b]{3}{*}{ Subject } & \multirow{2}{*}{\multicolumn{2}{|c|}{$\begin{array}{c}\text { Body water } \\
{ }^{2} \mathrm{H} \text { abundance (ppm) }\end{array}$}} & \multicolumn{4}{|c|}{$\begin{array}{c}\text { Fatty acid } \\
{ }^{2} \mathrm{H} \text { abundance (ppm) }\end{array}$} & \multicolumn{4}{|c|}{$\begin{array}{c}\text { Cholesterol } \\
{ }^{2} \mathrm{H} \text { abundance (ppm) }\end{array}$} & \multirow{2}{*}{\multicolumn{2}{|c|}{$\begin{array}{c}\text { Phospholipid } \\
{ }^{2} \mathrm{H} \text { abundance (ppm) }\end{array}$}} \\
\hline & & & \multicolumn{2}{|c|}{ Free } & \multicolumn{2}{|c|}{ Esterified } & \multicolumn{2}{|c|}{ Free } & \multicolumn{2}{|c|}{ Esterified } & & \\
\hline & Day 0 & $\begin{array}{l}\text { Average } \\
\text { over } 14 \mathrm{~d}\end{array}$ & Day 0 & Day 14 & Day 0 & Day 14 & Day 0 & Day 14 & Day 0 & Day 14 & Day 0 & Day 14 \\
\hline $\bar{A}$ & 153.6 & $770 \cdot 4$ & 131.8 & 162.4 & 125.2 & 217.5 & 122.8 & 201.8 & 118.1 & $224 \cdot 2$ & 131.4 & $185 \cdot 7$ \\
\hline$B$ & $154 \cdot 3$ & 651.4 & 137.4 & 141.0 & 124.2 & $170 \cdot 6$ & 122.9 & $181 \cdot 7$ & 116.2 & 185.6 & 129.3 & 201.5 \\
\hline$C$ & 153.8 & 706.5 & 137.8 & 139.6 & 128.9 & 140.2 & 132.7 & 169.1 & 120.0 & 221.2 & 133.5 & 168.0 \\
\hline D & 153.9 & 548.6 & 142.1 & 143.8 & $127 \cdot 7$ & $160 \cdot 3$ & 130.0 & $167 \cdot 4$ & 118.9 & 199.2 & 131.4 & 177.4 \\
\hline$E$ & 153.8 & $756 \cdot 1$ & 133.8 & 139.4 & 129.6 & $147 \cdot 3$ & 139.5 & 177.6 & $126 \cdot 4$ & 205.8 & $126 \cdot 2$ & - \\
\hline $\mathrm{F}$ & 152.9 & 703.1 & $138 \cdot 1$ & $137 \cdot 8$ & 128.4 & 139.9 & $130 \cdot 8$ & 155.8 & $120 \cdot 4$ & $170 \cdot 6$ & $131 \cdot 7$ & $166 \cdot 0$ \\
\hline Mean & $153 \cdot 7$ & 689.4 & $136 \cdot 8$ & 144.0 & $127 \cdot 3^{* *}$ & $162 \cdot 6$ & 129.8 & $175 \cdot 6$ & 120.0††† & $201 \cdot 1$ & $130 \cdot 6^{* \star}$ & $179 \cdot 7$ \\
\hline SEM & 0.2 & 33.0 & 1.5 & 3.8 & 0.9 & 12.0 & 2.6 & 6.4 & 1.4 & 8.4 & 1.0 & 5.9 \\
\hline
\end{tabular}
dance of the lipids was $20-30$ ppm below that of the body

Table 2. Deuterium $\left({ }^{2} \mathrm{H}\right.$ ) abundance of body water and circulating lipid before (day 0 ) and after (day 14 ) dosing with deuterium in six adult male subjectsł

Mean values were significantly different from that for day 0 free fatty acid ${ }^{2} \mathrm{H}$ abundance: ${ }^{*} P<0.01$.

Mean value was significantly different from that for day 0 free cholesterol ${ }^{2} \mathrm{H}$ abundance: $\dagger_{\dagger} P<0.001$.

$\ddagger$ For details of subjects and procedures, see Table 1 and pp. 228-229. 
water. This relative ${ }^{2} \mathrm{H}$ depletion in lipid has been reported elsewhere (Haggarty, 1990; Haggarty et al. 1990) and is the result of isotope discrimination against heavy $\mathrm{H}$ during reductive biosynthesis of fatty acids and cholesterol (Eidinof et al. 1953; Jungas, 1968). The ${ }^{2} \mathrm{H}$ abundance of esterified fatty acid (127.3 (SEM 0.9) ppm), derived from cholesterol ester and triacylglycerol, was significantly lower than that of free fatty acid (136.8 (SEM 1.5) ppm). The ${ }^{2} \mathrm{H}$ abundance of phospholipid (130.6 (SEM 1.0)) was also significantly different from that of free fatty acid, but in this case the whole compound was combusted, therefore some of the $\mathrm{H}$ will have been derived from the phospholipid head group and this comparison is less useful. It can also be seen from Table 2 that the ${ }^{2} \mathrm{H}$ abundance of esterified cholesterol (120.0 (SEM 1.4) $\mathrm{ppm}$ ) was significantly lower than that of free cholesterol (129.8 (SEM 2.6) ppm). The actual ${ }^{2} \mathrm{H}$ abundance within a lipid class will depend on the average abundance of that class obtained from the diet and the proportion synthesized de novo in the body. Therefore the observed differences in natural abundance may be due to different dietary sources of these compounds and/or a difference in the proportion synthesized endogenously. However, some general conclusions can be drawn from these differences. For example, we can deduce that significant proportions of these compounds are derived from distinct metabolic pools with different origins and that the free and esterified forms of both fatty acids and cholesterol are not in complete equilibrium.

At the end of the labelling period there was a significant increase in the ${ }^{2} \mathrm{H}$ abundance of all the lipid classes, with the order of increase being: esterified cholesterol (81.1 (SEM 2.2) $\mathrm{ppm}$ excess) $>$ phospholipid (48.3 (SEM 1.7) ppm excess) $>$ free cholesterol (45.8 (SEM 2.1) ppm excess) $>$ esterified fatty acid (35.3 (SEM 3.3) ppm excess) $>$ free fatty acid (7.2 (SEM 1.2) ppm excess). Care must be taken, however, in interpreting the phospholipid enrichment as this fraction was not hydrolysed to yield the pure fatty acid moiety before combustion and therefore may include some ${ }^{2} \mathrm{H}$ sequestered in the phospholipid head group as noted earlier.

The proportion of each fraction which had been synthesized during the labelling period (Table 3) was calculated from the average ${ }^{2} \mathrm{H}$ abundance of the body water, the increase in ${ }^{2} \mathrm{H}$ abundance in each lipid fraction, and the previously derived stoichiometry of water $\mathrm{H}$ incorporation into fatty acid and cholesterol (Jungas, 1968; Leitch \& Jones,
1993). The percentages synthesized were 2.3 (SEM 1.4 ) $\%$ for free fatty acid, 12.5 (SEM 4.0) $\%$ for esterified fatty acid, 16.2 (SEM 2.5) \% for cholesterol, 29.0 (SEM 3.1) \% for esterified cholesterol, and 16.2 (SEM 3.8) \% for phospholipid.

As reported by Leitch \& Jones (1993) in a similar study, we found a large degree of variability between individuals in rates of synthesis. Subject A in particular had a very high proportion of de novo synthesized free and esterified fatty acid; excluding this subject from the group yielded values for the proportions of free and esterified fatty acid synthesized de novo of 0.9 (SEM 0.3) \% and 9.3 (SEM 3.0)\% respectively. Because the value for subject A was so different from those of the other subjects the possibility must be considered that the value was in error because of a methodological error or because of violation of the assumptions underlying the calculation. If the high rate of synthesis for subject A were simply due to an error in the estimate of the plateau enrichment of ${ }^{2} \mathrm{H}$ in the body water during the labelling period we would expect to see the same effect for the other lipid classes, but the rates of synthesis of phospholipid and esterified cholesterol, for example, did not show the same pattern. Furthermore, the precision of measurement (SD 1.1 ppm) and the use of three internal standards in the analytical procedures lead us to the conclusion that the values for subject A were not the result of methodological errors. Some indication of the assumptions underlying the method may be obtained from the levels of circulating lipid. Although we did not measure these directly in plasma, the amounts of fatty acid and cholesterol recovered during the chromatographic isolation procedure were measured gravimetrically. Due to losses during extraction and isolation and variation in rates of recovery these values will be lower and more variable than measurements made directly in plasma but they do provide an indication as to the relative amounts of circulating lipid in the different subjects studied. There was no evidence of a difference between subject A and the rest of the group in the concentration of free fatty acid (overall mean 200 (SD 50) mg/l plasma), free cholesterol (overall mean 280 (SD 80) $\mathrm{mg} / \mathrm{l}$ ) or esterified cholesterol (overall mean 390 (SD 190) $\mathrm{mg} / \mathrm{l}$ ). However, the value for circulating esterified fatty acid in subject A $(1370 \mathrm{mg} / \mathrm{l})$ was five times that of the mean of the rest of the group (250 (SD 90) $\mathrm{mg} / \mathrm{l}$ ). This suggests either a condition of hypertriacylglycerolaemia in subject A or that this subject had taken

Table 3. Proportion of circulating lipid which had been synthesized de novo measured by ${ }^{2} \mathrm{H}$ incorporation over $14 \mathrm{~d}$, in six adult male subjects

\begin{tabular}{|c|c|c|c|c|c|}
\hline \multirow[b]{2}{*}{ Subject } & \multicolumn{2}{|c|}{$\begin{array}{c}\text { Fatty acid } \\
\text { synthesized de novo (\%) }\end{array}$} & \multicolumn{2}{|c|}{$\begin{array}{c}\text { Cholesterol } \\
\text { synthesized de novo (\%) }\end{array}$} & \multirow{2}{*}{$\begin{array}{c}\text { Phospholipid } \\
\text { synthesized de novo (\%) }\end{array}$} \\
\hline & Free & Esterified & Free & Esterified & \\
\hline $\bar{A}$ & 9.4 & 28.2 & 24.2 & 32.5 & $16 \cdot 6$ \\
\hline$B$ & 1.4 & $17 \cdot 6$ & $22 \cdot 3$ & $26 \cdot 3$ & $27 \cdot 4$ \\
\hline $\mathrm{C}$ & 0.6 & 3.9 & 12.4 & 34.6 & 11.8 \\
\hline D & 0.8 & $15 \cdot 6$ & 17.9 & 38.4 & $22 \cdot 0$ \\
\hline$E$ & 1.8 & 5.5 & 11.9 & 24.9 & - \\
\hline $\mathrm{F}$ & 0 & 3.9 & 8.6 & $17 \cdot 2$ & 3.3 \\
\hline Mean & $2 \cdot 3$ & $12 \cdot 5$ & $16 \cdot 2$ & 29.0 & $16 \cdot 2$ \\
\hline SEM & 1.4 & 4.0 & 2.5 & 3.1 & 3.8 \\
\hline
\end{tabular}


food before sampling, conditions which would invalidate the assumptions underlying the methodology. However, even excluding subject $A$, it can be seen from Table 3 that there was considerable variability in the rates of synthesis of all the lipid classes in the five other subjects.

Within the fatty acid and cholesterol fractions, a high rate of synthesis was associated with a low pre-dose ${ }^{2} \mathrm{H}$ abundance as would be expected from the known ${ }^{2} \mathrm{H}$ isotope discrimination effect during synthesis of lipids (Jungas, 1968). For esterified fatty acid there was a significant correlation $\left(r^{2} 68.3 \% ; P=0.043\right)$ between the rate of synthesis and the pre-dose ${ }^{2} \mathrm{H}$ abundance. The relationship achieved borderline significance for free cholesterol $\left(r^{2} 64.2 \% ; P=\right.$ $0.055)$ but for free fatty acid $\left(r^{2} 55.3 \% ; P=0.090\right)$, phospholipid $\left(r^{2} 45.1 \% ; P=0.214\right)$ and esterified cholesterol $\left(r^{2} 8.3 \% ; P=0.579\right)$ the relationship was not statistically significant.

Assuming that the circulating non-esterified fatty acids are derived from the body fat stores following an overnight fast and noradrenaline infusion, the proportion of nonesterified fatty acid which has been synthesized de novo over the labelling period (Table 3 ) can be used to estimate the rate of whole-body fatty acid synthesis if the body fat content is known (Table 1). The resulting rates of wholebody fatty acid synthesis (Table 4) show that the average rate of synthesis for the group was $30 \mathrm{~g} / \mathrm{d}$. However, this value is heavily influenced by the rate of synthesis calculated for subject A $(142 \mathrm{~g} / \mathrm{d})$. The mean for the rest of the group was only $8 \mathrm{~g} / \mathrm{d}$. These rates of synthesis translate into an error on the DLW-derived estimates of $\mathrm{CO}_{2}$ production of -2.5 litres/d (or -9.6 litres/d including subject A). Assuming a typical rate of $\mathrm{CO}_{2}$ production in subjects of this body weight, expending 1.6 times their estimated BMR (Department of Health, 1991) and with a food quotient of $0 \cdot 86$, i.e. typical values for adult males performing non-manual work, the resulting percentage error on DLW-derived estimates of $\mathrm{CO}_{2}$ production would be $-2 \%$ for the group as a whole and only $-0.5 \%$ excluding subject A.

\section{Discussion}

In order to calculate the error on DLW-derived $\mathrm{CO}_{2}$ production introduced by fat synthesis it is necessary to know the absolute rate of whole-body synthesis over the period of the DLW study. This can be obtained from knowledge of the size of the body fat pool and the proportion of a representative sample of body fat which has been synthesized over the period of interest. This information is, however, relatively difficult to obtain as the site of sampling should be representative of the whole-body stores and the experiment may have to be carried out over a relatively long period in order to allow a sufficient level of isotope incorporation. Because of these difficulties human fatty acid synthesis has previously been estimated over relatively short periods from measurements of the incorporation of label into triacylglycerol exported by the liver.

Using this approach, Leitch \& Jones (1993) obtained a value of $8 \%$ (range $5-15 \%$ ) in subjects given liquid meals every $4 \mathrm{~h}$ with a fat composition typical of the Western diet (32\% energy as fat). Using a similar approach, but over a much longer period, in subjects whose diets should also contain about $30 \%$ energy as fat (Begom \& Singh, 1995, 1997) we found that $9.3 \%$ (12.5\% including subject A) of the esterified fatty acid had been synthesized de novo during the $14 \mathrm{~d}$ experimental period. In the present study the ${ }^{2} \mathrm{H}$ incorporation was measured in the fasted state but Leitch \& Jones (1993) measured synthesis in subjects given a liquid meal every $4 \mathrm{~h}$. However, because the blood samples for isotopic analysis were taken immediately before each meal, and therefore $4 \mathrm{~h}$ after the previous meal, these authors argued that dietary fat in chylomicrons will have been removed from the circulation. These authors also found that the proportion of esterified fatty acid in the circulation which had been synthesized de novo had plateaued at about $24 \mathrm{~h}$ after administration of ${ }^{2} \mathrm{H}_{2} \mathrm{O}$ and that it remained constant for the next $24 \mathrm{~h}$, suggesting that their results for hepatic triacylglycerol synthesis are experimentally comparable with those presented here. Furthermore, the agreement

Table 4. Effect of fatty acid synthesis on estimates of $\mathrm{CO}_{2}$ production derived from doublylabelled water (DLW) methodology, in six adult male subjects

\begin{tabular}{|c|c|c|c|}
\hline Subject & $\begin{array}{l}\text { Fatty acid synthesis } \\
\qquad(\mathrm{g} / \mathrm{d})^{*}\end{array}$ & $\begin{array}{l}\text { Error on DLW-derived } \\
\mathrm{CO}_{2} \text { production } \\
\text { (litres } / \mathrm{d}) \dagger\end{array}$ & $\begin{array}{l}\text { Error on DLW-derived } \\
\mathrm{CO}_{2} \text { production } \\
(\%) \ddagger\end{array}$ \\
\hline $\bar{A}$ & 142 & -45.4 & -9.1 \\
\hline B & 11 & -3.7 & -0.8 \\
\hline C & 4 & $-1 \cdot 2$ & -0.2 \\
\hline D & 2 & -0.8 & -0.2 \\
\hline $\mathrm{E}$ & 21 & $-6 \cdot 7$ & $-1 \cdot 3$ \\
\hline $\mathrm{F}$ & 0 & 0.0 & 0.0 \\
\hline Mean & $30 \cdot 2$ & $-9 \cdot 6$ & -1.9 \\
\hline SEM & $22 \cdot 6$ & $7 \cdot 2$ & 1.4 \\
\hline
\end{tabular}

* Calculated from the body fat content (Table 1) and the proportion of circulating free fatty acid synthesized over the $14 \mathrm{~d}$ experimental period (Table 3 ).

† Stoichiometry of the effect of sequestration on DLW-derived $\mathrm{CO}_{2}$ production is -0.319 litres $\mathrm{CO}_{2}$ per $\mathrm{g}$ fat synthesized (Haggarty, 1990; Haggarty et al. 1990).

‡ Typical $\mathrm{CO}_{2}$ production estimated assuming energy expenditure $=1.6 \times$ predicted BMR (Department of Health, 1991) and an RQ of 0.86 (Haggarty et al. 1997). 
between the values for hepatic triacylglycerol synthesis, obtained over very different time periods $(1-2 \mathrm{~d} v .14 \mathrm{~d})$, suggests that very little of the esterified fatty acid of hepatic origin is derived from free fatty acid mobilized from adipose tissue. Leitch \& Jones (1993) calculated a lipogenic rate of $1.7 \mathrm{~g} / \mathrm{d}$ using the value of $8 \%$ synthesis de novo and the mid-point of published values for VLDL-triacylglycerol production rates $(300 \mathrm{mg} / \mathrm{kg}$ per d) to estimate a VLDLtriacylglycerol flux in their subjects of $21.6 \mathrm{~g} / \mathrm{d}$. For the subjects described here, a VLDL-triacylglycerol production rate of $300 \mathrm{mg} / \mathrm{kg}$ per d would also result in an absolute synthetic rate of $1.7 \mathrm{~g} / \mathrm{d}(2.3 \mathrm{~g} / \mathrm{d}$ including subject $\mathrm{A})$. The spread of values for esterified fatty acid obtained by Leitch \& Jones $(1993 ; 5-15 \%)$ and those reported here (4-18\% excluding subject A) suggests that the normal betweensubject variation is considerable. The results for hepatic fatty acid synthesis of about $2 \mathrm{~g} / \mathrm{d}$ obtained by Leitch \& Jones (1993) and presented here would still only result in an error of about $-0.2 \%$ on the DLW method. The diet of typical Indian males is probably slightly lower in fat and cholesterol than the typical Western diet although our synthesis rates have primarily been compared with those of Leitch \& Jones (1993) who gave subjects a liquid meal containing $32 \%$ fat which is very similar to the diet of Indian males. However, such estimates of hepatic lipogenesis may not necessarily reflect whole-body lipogenesis as they are based on a number of assumptions and they specifically exclude any extrahepatic fatty acid synthesis.

A more reliable estimate of whole-body lipogenesis may be obtained from the fatty acids stored in the adipose tissue as this would include the esterified fatty acid produced by the liver as well as that synthesized in the adipose and other extra-hepatic tissue. However, direct sampling of the adipose tissue fatty acids for evaluation of ${ }^{2} \mathrm{H}$ incorporation is problematic as it would involve biopsy and even if this were possible, different adipose sites turn over at different rates (Sjostrom, 1973) and it would not be feasible to sample those deep within the body. Another approach is to sample those free fatty acids in the circulation which have been mobilized from the body stores as a whole and this was the approach adopted in the present study. The purpose of the noradrenaline infusion after overnight fast was to maximize the proportion of circulating free fatty acid which had been mobilized from adipose tissue. Under these conditions we found that $0.9 \%$ of the circulating free fatty acid had been synthesized de novo during the $14 \mathrm{~d}$ experimental period (2.3\% including subject A); Leitch \& Jones (1993) did not measure the synthesis of circulating free fatty acids. This would result in a value for whole-body fatty acid synthesis of $7.6 \mathrm{~g} / \mathrm{d}(30.2 \mathrm{~g} / \mathrm{d}$ including subject A). This calculation involved two assumptions: (1) that the free fatty acid mobilized after an overnight fast and noradrenaline infusion is derived from the body lipid stores, and (2) that the mobilized fatty acids are representative of the body stores. It is known that the plasma non-esterified fatty acid concentration is determined by the rate of release of fatty acids from adipose tissue (Armstrong et al. 1961; Issekutz et al. 1967) and more recent work by Halliwell et al. (1996) on the arterio-venous concentration difference of individual fatty acids across an adipose tissue site in relation to the concentration in the adipose tissue after an overnight fast, indicates that, although there is some selectivity in the net release of individual fatty acids, for the quantitatively important fatty acids in the adipose tissue $\left(\mathrm{C}_{14}\right.$ to $\left.\mathrm{C}_{18}\right)$ the arterio-venous difference is generally related to the molar concentration in the adipose tissue.

When estimating the effect of lipogenesis on the DLW method it is whole-body, rather than just hepatic, lipogenesis which is the variable of interest, therefore the estimate of the former, obtained from the circulating non-esterified fatty acids, was used to estimate the effect of lipogenesis on the DLW method. Using these results for whole-body fatty acid synthesis we found little evidence of an error on DLWderived $\mathrm{CO}_{2}$ production for five of the six subjects studied; mean $-0.5 \%$, range 0 to $-1.3 \%$. Given the already very low rate of synthesis of free fatty acid in all but subject $\mathrm{A}$ it is not surprising that the level of whole-body fatty acid synthesis was not detectable in one of the subjects. Lipogenesis was detectable in this subject in the esterified fatty acid fraction although this was also one of the lowest rates of the group as a whole. However, the error on DLW-derived $\mathrm{CO}_{2}$ production for the remaining subject was substantial $(-10 \%)$. We have argued that the measured ${ }^{2} \mathrm{H}$ abundance in this individual gives a true indication of the proportion of the circulating fatty acid which has been synthesized de novo but that the very high value for circulating triacylglycerol (five times that of the mean of the other five subjects) indicates that the assumptions underlying the calculation of whole-body lipogenesis may be invalid.

It has also been shown that in animals, even at very low rates of growth, fat synthesis occurs but that the rate of synthesis is insufficient to have an important effect on the DLW method (Midwood et al. 1993; Haggarty et al. 1994). For five of the six human subjects studied here, the mean rate of synthesis was $122 \mathrm{mg} / \mathrm{kg}$ body weight. This compares with about $290 \mathrm{mg} / \mathrm{kg}$ body weight in pigs (Haggarty et al. 1990) and $125 \mathrm{mg} / \mathrm{kg}$ body weight in sheep (Midwood et al. 1993) with very modest rates of weight gain.

The results presented here show that, at the end of the $14 \mathrm{~d}$ labelling period, the proportion of circulating esterified cholesterol which was synthesized de novo (29\%) was almost double that for free cholesterol (16\%). These results are consistent with the proposal that most of the cholesterol synthesis in man is extrahepatic (Spady \& Dietschy, 1983; Dietschy et al. 1993) since most of the cholesterol released from the liver is secreted as free cholesterol whilst the cholesterol released from the extrahepatic tissues during reverse cholesterol transport is thought to be in the form of esterified cholesterol carried initially by HDL particles (Norum et al. 1983; Mackness \& Durrington, 1992). We estimate a cholesterol synthetic rate of $0.3 \mathrm{~g} / \mathrm{d}$ using free and $0.5 \mathrm{~g} / \mathrm{d}$ using esterified cholesterol. These results are fairly close to the estimated rate of cholesterol synthesis of $0.7 \mathrm{~g} / \mathrm{d}$ for a $70 \mathrm{~kg}$ man, consuming a typical Western diet (Dietschy et al. 1993). These rates of synthesis translate into negligible errors on the DLW method, therefore cholesterol synthesis can be excluded as a potential source of error.

For compounds that turn over slowly, such as cholesterol and body fat, it is apparent that long labelling periods would be required to achieve a true steady state with respect to all the pools in the body. The resulting experimental protocol would be very difficult to carry out in human volunteers. 
However, the data presented here suggest that at least some of this information may be obtained from an analysis of natural variations in ${ }^{2} \mathrm{H}$ abundance. Such variation reflects events occurring over long periods and therefore it can be assumed that a steady state has been reached with respect to this marker of synthesis. Since the natural ${ }^{2} \mathrm{H}$ abundance was significantly lower in esterified than free cholesterol, this supports the proposal that more of the esterified than free cholesterol was synthesized in the subjects studied here and that the circulating free and esterified cholesterol are derived from different metabolic pools in the body. Similarly, evidence that circulating esterified and free fatty acid are derived from different metabolic pools with different rates of synthesis is to be found in the natural variation in ${ }^{2} \mathrm{H}$ abundance between these pools. The results presented here show that the natural ${ }^{2} \mathrm{H}$ abundance in lipids is related to the level of synthesis, with the lowest abundances associated with the highest rates of synthesis. Therefore, the observation of higher rates of synthesis, of esterified than free fatty acid are consistent with the observation of a significantly lower natural ${ }^{2} \mathrm{H}$ abundance in the esterified fatty acids. Thus, even in the absence of tracer experiments, natural variations in the ${ }^{2} \mathrm{H}$ abundance in lipid classes can provide information on whether they constitute distinct metabolic pools with different origins. With further work, this approach of exploiting natural variations in ${ }^{2} \mathrm{H}$ abundance may also yield quantitative information on rates of synthesis.

\section{Acknowledgements}

This research was supported by the International Atomic Energy Agency and the Scottish Office Agriculture, Environment and Fisheries Department.

\section{References}

Armstrong DT, Steele R, Altszuler N, Dunn A, Bishop JS \& DeBodo WM (1961) Regulation of plasma free fatty acid turnover. American Journal of Physiology 201, 9-15.

Begom R \& Singh RB (1995) Prevalence of coronary artery disease and its risk factors in the urban population of south and north India. Acta Cardiologica 50, 227-240.

Begom R \& Singh RB (1997) Association of higher saturated fat intake with higher risk of hypertension in an urban population of Trivandrum in South India. International Journal of Cardiology 58, 63-70.

Bligh EG \& Dyer WJ (1959) A rapid method of total lipid extraction and purification. Canadian Journal of Biochemistry and Physiology 37, 911-917.

Department of Health (1991) Dietary Reference Values for Food Energy and Nutrients for the United Kingdom. Report on Health and Social Subjects no. 41. London: H.M. Stationery Office.

Dietschy JM \& Spady DK (1984) Measurement of rates of cholesterol synthesis using tritiated water. Journal of Lipid Research 25, 1469-1476.

Dietschy JM, Turley SD \& Spady DK (1993) Role of liver in the maintenance of cholesterol and low density lipoprotein homeostasis in different animal species, including humans. Journal of Lipid Research 34, 1637-1659.

Eidinof ML, Perri GC, Knoll JE, Marano BJ \& Arnheim J (1953) The fractionation of hydrogen isotopes in biological systems. Journal of the American Chemical Society 75, 240-248.
Goodman DeWS, Noble RP \& Dell RB (1973) Three-pool model of long-term turnover of plasma cholesterol in man. Journal of Lipid Research 14, 178-188.

Haggarty P (1990) The effect of isotope sequestration on the performance of the heavy water technique for measuring energy expenditure. In The Doubly-labelled Water Method of Measuring Energy Expenditure, pp. 114-146 [AM Prentice, editor]. Vienna: International Atomic Energy Agency.

Haggarty P, Franklin MF, Fuller MF, MacGaw BA, Christie SL, Milne E, Duncan G \& Smith JS (1994) Validation of the doubly labeled water method in growing pigs. American Journal of Physiology 267, R1574-R1588.

Haggarty P, McGaw BA, Fuller MF, Christie SL \& Wong WW (1990) Water hydrogen incorporation into body fat in growing pigs; its effect on the double and triple labeled water methods. American Journal of Physiology 260, R627-R634.

Haggarty P, Valencia ME, McNeill G, Moya SY, Pinelli A, Quihui L, Davalos R, Ashton J, Milne E \& James WPT (1997) Energy expenditure during heavy work and its interaction with body weight. British Journal of Nutrition 77, 359-373.

Halliwell KJ, Fielding BA, Samra JS, Humphreys SM \& Frayn KN (1996) Release of individual fatty acids from human adipose tissue in vitro after an overnight fast. Journal of Lipid Research 37, 1842-1848.

Hellerstein MK, Christiansen M, Kaempfer S, Kletke C, Wu K, Reid JS, Mulligan K, Hellerstein NS \& Shackleton CHL (1991) Measurement of de novo hepatic lipogenesis in humans using stable isotopes. Journal of Clinical Investigation 87, 18411852.

Issekutz B, Bortz WM, Miller HI \& Paul P (1967) Turnover rate of plasma FFA in humans and in dogs. Metabolism 16, 10011009.

Jones PH, Lichtenstein AH \& Schaefer EJ (1994) Interaction of dietary fat saturation and cholesterol level on cholesterol synthesis measured using deuterium incorporation. Journal of Lipid Research 35, 1093-1101.

Jones PH, Scanu AM \& Schoeller DA (1988) Plasma cholesterol synthesis using deuterated water in humans: effect of short-term food restriction. Journal of Laboratory and Clinical Medicine 111, 627-633.

Jungas RL (1968) Fatty acid synthesis in adipose tissue incubated in tritiated water. Biochemistry 7, 3708-3717.

Kaluzny MA, Duncan LA, Merit MV \& Epps DE (1985) Rapid separation of lipid classes in high yield and purity using bonded phase columns. Journal of Lipid Research 26, 135-140.

Leitch CA \& Jones PJH (1991) Measurement of triglyceride synthesis in humans using deuterium oxide and isotope ratio mass spectrometry. Biological Mass Spectrometry 20, 392-396.

Leitch CA \& Jones PJH (1993) Measurement of human lipogenesis using deuterium incorporation. Journal of Lipid Research 34, 157-163.

Lifson N \& McLintock R (1966) Theory of the use of turnover rates of body water for measuring energy and material balance. Journal of Theoretical Biology 12, 46-74.

Mackness MI \& Durrington PN (1992) Lipoprotein separation and analysis for clinical studies. In Lipoprotein Analysis, pp. 1-42 [CA Converse \& ER Skinner, editors]. Oxford: Oxford University Press.

Midwood AJ, Haggarty P \& McGaw BA (1993) The doubly labeled water method; errors due to deuterium exchange and sequestration in ruminants. American Journal of Physiology 264, R561-R567.

Norum KR, Berg T, Helgerud P \& Drevon CA (1983) Transport of cholesterol. Physiological Reviews 63, 1343-1419.

Ritenberg D \& Schoenheimer R (1937) Deuterium as an indicator in the study of intermediary metabolism. Journal of Biological Chemistry 121, 235-253. 
Sjostrom L (1973) Carbohydrate stimulated fatty acid synthesis de novo in human adipose tissue of different cellular types. Acta Medica Scandinavica 194, 387-404.

Snyder WS, Fish BR, Bernard SR, Ford MR \& Muir JR (1968) Urinary excretion of tritium following exposure of man to HTO - a two exponential model. Physics in Medicine and Biology 13, 547-559.
Spady DK \& Dietschy JM (1983) Sterol synthesis in vivo in 18 tissues of the squirrel monkey, guinea pig, rabbit, hamster, and rat. Journal of Lipid Research 24, 303-315.

Wong WW, Hachey DL, Insull W, Opekun AR \& Klein PD (1993) Effect of dietary cholesterol on cholesterol synthesis in breastfed and formula-fed infants. Journal of Lipid Research 34, $1403-1411$. 